\title{
Selected Legal Problems of Online Advertising
}

\begin{abstract}
AlEKSANDRA NOWAK-GRUCA
Abstract The aim of this article is to analyse the most important issues related to the latest forms of online advertising. In particular, appreciating the importance of online advertising in the development of the information society, the question is then raised about the legal limits of the admissibility of advertising, which is invasive, insistent or contains hidden meaning, inaccessible to the recipient's awareness of content. This issue has been presented from the perspective of European Union (EU) law, in the context of selected directives relevant for online advertising. The problem raised in the article deserves to be developed because we observe a sharp increase in the importance of the Internet, and the online advertising issue has not been the subject of comprehensive regulation in EU law.
\end{abstract}

Keywords: • online advertising • native advertising • product placement • unfair competition $\bullet$ integrity in advertising •

CORRESPONDENCE ADDRESS: Aleksandra Nowak-Gruca, PhD, Cracow University of Economics, Department of Civil and Economic Law, Rakowicka 27, 31-510 Crakow, Poland, e-mail: alexandra.nowak@interia.pl.

DOI 10.18690/lexonomica.10.1.33-44.2018 UDC: 659.1:004:347.7(4)

ISSN 1855-7147 Print / 1855-7155 On-line C) 2018 University of Maribor Press

Available at: http://journals.um.si/index.php/lexonomica. 


\section{A. Nowak-Gruca: Selected Legal Problems of Online Advertising}

1 Introduction

Advertising is now ubiquitous. On the one hand, in a modern, information society, advertising has become an important element in shaping the attractiveness of the entrepreneur, in other words its marketing success, while on the other it has proved to be one of the conditions for optimal use of market goods and services by consumers. It also plays an important role in the economic expansion of the European media market (Makowiec, 2014: 12). Advertising is also an interdisciplinary issue, in the sense that it is currently the subject of interest in many disciplines, namely economics, marketing, management, psychology, sociology, law, while even in neuroscience is advertising becoming more significant (Lee, Broderick, Chamberlain, 2007: 199-204). The effectiveness of the advertising message depends on the knowledge from many fields of science, because the overwhelming desire to have a product or use the service requires an effective impact on the recipient of the message. Although advertising has become an inseparable element of the reality that surrounds us today, its ubiquitousness makes recipients more and more indifferent and resistant to its impact. Thus, it is not surprising that advertising specialists are looking for newer, cleverer ways of communication with clients, using reports of cognitive and human sciences, to create increasingly sophisticated techniques of influencing the recipient of advertising messages. Due to the popularity and accessibility of the Internet, which acts almost as a daily communication and research tool, we are witnessing the burgeoning of various forms of on-line communication aimed at creating the demand for specific goods or services. In today's online marketing, in addition to such forms of online advertising, such as: e-mailing, display advertising (graphical), affiliate marketing and remarketing, sponsored link, sponsored article, positioning, banners, pop-ups, etc., we find many messages that give the impression of being neutral information. In online marketing, native advertising, or so-called sly product placement, is growing in popularity today. However, these advertisements often affect the recipient in a hidden manner. Advertising should meet the minimum standards set by the law. However, the effectiveness of the application of the law of advertising depends on the shaping of legal regulations, the practice of applying these regulations and the legal consciousness of society. In this context, the question about the legal limits of integrity in advertising should be resumed, which is the main purpose of this article.

Achieving this goal requires presenting the issue of online advertising and indicating the directions of its development against the background of the admissibility of new forms of advertising in the light of EU law. Therefore, it is necessary to present regulations in selected EU directives relating to this issue, with the awareness that grasping the legal admissibility of advertising goes beyond the scope of one article.

The article is divided into three parts. The first part presents the problems of online advertising and indicates the possible directions of its development. The second part focuses on selected legal problems concerning, in particular, hidden and native advertising in the light of selected EU directives. The article closes with a summary, in which the legal limits of advertising on the Internet were set and an attempt was made to 


\section{LEXONOMICA \\ A. Nowak-Gruca: Selected Legal Problems of Online Advertising}

answer the question whether current regulations are sufficient in the context of new phenomena and new techniques of affecting the recipient by advertisers.

\section{The development of advertising on the Internet}

It should be pointed out that advertising has gained significant importance in one's daily life, especially thanks to the invention in 1442 by Johannes Gutenberg's Printing Press. From that moment in history, advertisements have changed in the terms of quality and quantity, and have become an indispensable tool in the fight for the consumer. It was also influenced by the development of mass media: the press (newspapers), radio, television and the Internet, which all allowed advertising to exert more and more influence on the lives of societies (Grzybczyk, 2008: 14; Makowiec, 2014: 15).

After analyzing the problems of advertising on the Internet, it is not difficult to notice that online advertising is fundamentally different from traditional advertising. The Internet creates a specific form of communication that can be placed somewhere between mass communication and individual communication (Barta, Markiewicz, 1998: 35). It is also not difficult to notice that the Internet is an extremely attractive advertising medium, because it has specific marketing features that are unavailable in the case of other media like press, radio, television, etc. Technical advantages over other forms of advertising provide it with features such as:

- global reach and constantly increasing number of users;

- relatively low cost of advertising on the web (when compared to TV or radio commercials);

- relative durability of the advertisement, which does not disappear as quickly as, advertising on TV or a 15 second radio commercial.

In connection with the globalization of markets, as well as improving communication among people, the Internet is currently a very important medium and has the largest number of active users. Therefore, it owns a significant amount of the increase of online advertising in the advertising market as well as in marketing budgets. Online advertising takes many forms, some of which are used in a manner consistent with the common ethics of the profession, but some do not adapt to these requirements. In online advertising, in addition to forms such as banners, mailing, sponsoring and buying keywords in search engines, new forms of impact on the Internet user appear to attract one's attention, which requires more and more advanced incentives (Benjamin, Ostrovsky, Schwarz, 2007: 242). The creators of online ads resort to invasive forms such as pop-up ad's, mousetrapping and overlayer ads. The first one is in the form of pop-up windows in the user's browser window and is activated without the user's initiative. This advertisement should offer the user the possibility of closing it or having the ad disappear after a dozen or so seconds. Mousetrapping ads block the Internet user and the overlayer advertisement is a kind of pop-up ad. When the user tries to close an overlayer, the advertisement moves to a different place on the screen and only with few clicks on the small icon of the „close" button will give the desired result. Internet advertising uses, among others flashing 
banners, which distracts the user's attention, or blinding windows, which pose as error messages in the operating system, are not advertising. However, overloading Internet users with advertising content, sometimes referred to as the phenomenon of banner blindness (Chan, 2009:227), which consists in immediately ignoring the content that looks like advertising, caused marketing specialists to manipulate the advertisements even more for content that would present the advertised product subtly. That is why in online marketing we observe the growing popularity of native advertising.

What is native advertising? Promoters, companies and journalists proposed various definitions, but failed to reach a mutual conclusion. Native advertising is usually defined as advertiser-sponsored content that is designed to appear to the user as similar to editorial content (Manic, 2015: 53-58). Native advertising can take the form of a sponsored article, content-type content, but it can also be a sponsored post on Facebook and other social media platforms, with non-reflective graphics in the picture illustrating some news, video content, text in a paper book or newspaper, or a placement product. The common point of these messages is that, in principle, a native ad cannot be annoying. It is indicated that the creator of such an advertisement must display a lot of manipulation, skill and intuition to create good material that matches the requirements of native advertising.

Native advertising is a form of paid media where the ad experience follows the natural form and function of the user experience in which it is placed. Native ads match the visual design of the experience they live within, and not only look, but also feel like natural content (form) and must behave consistently with the native user experience, while at the same time function just like natural content (function). The largest social platforms in the world monetize with native, in-feed ads, including Facebook, Twitter, Instagram, and Tumblr. The publishing industry is quickly following suit, as companies such as Time Inc, Forbes, Wall Street Journal, New York Times, and USA Today continue to introduce new advertising integrations on desktop and mobile devices that match both the form \& function of their editorial feeds. ${ }^{1}$

Some studies have reported positive audience reaction to online native advertising (Wojdynski, Evans, 2015: 157-168). Tutaj and Van Reijmersdal (2012: 5-18) found that users display lower ad scepticism toward native advertising as compared to banner advertisements, and find the content less irritating and more informative and amusing. Therefore, it is not surprising that in social media, the so-called sly product placement is gaining the popularity among marketers. Contemporary studies of consumer behaviour show that in a world overloaded with advertising messages, traditional product placement does not fulfill its role. It turns out that if product placement is obvious and ostentatious, then the product promoted in this way in the eyes of recipients becomes less attractive. People do not like to be manipulated, which is reflected in the research results carried out in this area (Brehm, 2009: 384). Nevertheless, if a given product is not shown in an intrusive way, for example it appears in the background, it turns out to be more attractive to the recipients. Therefore, it is not surprising that these reports have been picked up by the creators of advertising and become a desirable tool for marketing specialists. This is how sly product placement was born. Well-known figures from the world of media or 


\section{LEXONOMICA

sports publish their photos on social media, on which there are known brands or their recognizable products or other characteristic elements, recalling the recipient's association with a given producer or supplier of a given $\operatorname{good}^{2}$. Such actions can easily be mislead by consumers as to whether they are dealing with ordinary information, with luck, with real fascination with a given product or with advertising.

Meanwhile EU legislators, followed by national legislation in the Member States, have been making intense efforts to protect the truth as a foundation for fairness of competition and undistorted market exchange and it is not surprising that advertising was of key interest of the EU legislation. It is emphasized that any misleading market messages limit the consumer's right to self-determination and can negatively affect competition. Therefore, due to the need to protect competition and consumers, it is necessary to set the legal framework for the admissibility of this type of marketing activity, which is most often in a veiled, indirect or even hidden way affecting the recipients and their purchasing decisions.

\section{Legal limits of online advertising in light of European Union directives - selected issues}

The first laws regulating advertising activities were created in the first half of the twentieth century. One of the first regulations was titled "Standards of Conduct", which was created by the American Association of Advertising Agencies (AAAA) in 1916. At present, there are many legal acts regulating the advertising market in EU law, among which we can distinguish horizontal provisions that apply to all forms of advertising and specific provisions relating to the advertising of a given type of product or services. Below, due to the framework of the article, only selected regulations relevant from the perspective of the online advertising forms discussed above will be presented.

The legal definition of advertising can be found in Art. 2(a) of the Directive 2006/114/EC of the European Parliament and of the Council of 12 December 2006 concerning misleading and comparative advertising ${ }^{3}$ (Directive 2006/114/EC). According to the mentioned provision 'advertising' means the making of a representation in any form in connection with a trade, business, craft or profession in order to promote the supply of goods or services, including immovable property, rights and obligations. In light of the case-law of the Court of Justice of the EU (CJEU), advertising is also a service within the meaning of Art. 49 of the EC Treaty (now Article 56 Treaty on the Functioning of the EU; TFEU), which primarily fulfills an information function. ${ }^{4}$ The Directive 2006/114/EC also defines the concept of misleading advertising. 'Misleading advertising' means any advertising that in any way, including its presentation, deceives or is likely to deceive the persons to whom it is addressed or whom it reaches and which, by reason of its deceptive nature, is likely to affect their economic behaviour or which, for those reasons, injures or is likely to injure a competitor (Art. 2 (b)). In accordance with Art. 3 in determining whether advertising is misleading, the account shall be taken of all its features, and in particular of any information it contains concerning: the characteristics of goods or services, such as their availability, nature, execution, composition, method 
and date of manufacture or provision, fitness for purpose, uses, quantity, specification, geographical or commercial origin or the results to be expected from their use, or the results and material features of tests or checks carried out on the goods or services;

- the price or the manner in which the price is calculated, and the conditions on which the goods are supplied or the services provided;

- the nature, attributes and rights of the advertiser, such as his/her identity and assets, his/her qualifications and ownership of industrial, commercial or intellectual property rights or his/her awards and distinctions.

Let us assume that the advertisement consists of two elements: information about a product or service and persuasive content aimed at persuading a customer to purchase or use specific goods or services, the element of encouragement should not completely obscure information about the offer. Thus, an online ad that exaggerates the importance of bonuses to a product or service might be considered misleading. An advertisement is not misleading if it does not cause its recipients to mislead about advertised goods or services and is not able to influence the recipients' decisions regarding the purchase of such goods or services. It is also worth noting that misleading actions are also regulated in the Directive 2005/29/EC of the European Parliament and of the Council of 11 May 2005 concerning unfair business-to-consumer commercial practices in the internal market $^{5}$ (Directive 2005/29/EC). The CJEU, in one of the judgments, pointed out that Art. 7(1) and (3) of Directive 2005/29/EC must be interpreted as the following; for the purposes of assessing whether a commercial practice must be regarded as a misleading omission, consideration should be given to the context in which that practice takes place, in particular the limitations of the communications medium used for the purposes of that commercial practice, the limitations of time and space imposed by that communications medium and any measures taken by the trader to make the information available to consumers by other means, even though that requirement is not expressly referred to in the wording of the national legislation in question. Art. 6(1) of Directive 2005/29/EC must be interpreted as meaning that a commercial practice which consists of dividing the price of a product into several components and highlighting one of them, must be regarded as misleading, since that practice would be likely, first, to give the average consumer the false impression that he/she has been offered a favourable price and, secondly, cause $\mathrm{him} / \mathrm{her}$ to take a transactional decision that he/she would not have taken otherwise. It is then up to the court to take into account all the relevant circumstances of the main proceedings. ${ }^{6}$

The main problem associated with placing ads on the Internet is their excessive nuisance through their insistent presentation, for example an overlayer ad that covers an important part of the website, or one that is difficult to close. An ad blocking the Internet user's freedom, so-called mousetrapping, can be considered as an aggressive market practice within the meaning of Art. 8 of the Directive 2005/29/EC. According to this provision a commercial practice shall be regarded as aggressive if, in its factual context, taking account of all its features and circumstances, by harassment, coercion, including the use of physical force, or undue influence, it significantly impairs or is likely to significantly 


\section{LEXONOMICA

impair the average consumer's freedom of choice or conduct with regard to the product and thereby causes him/her or is likely to cause him/her to make a transactional decision that he/she would not have taken otherwise.

Referring to currently popular marketing techniques such as native advertising and sly product placement, the above description of the native advertising allows us to put forward the thesis that the native ad falls somewhere between the subliminal advertising and the hidden ad. It is also related to product placement. However, it should be emphasized that according to previous assumptions, the content of native advertising more than in the case of other forms of advertising - may come close to information. It is worth trying to set the legal boundaries of these concepts.

In the context of native advertising, attention should first be directed at the Directive 2010/13/EU of the European Parliament and of the Council of 10 March 2010 on the coordination of certain provisions administered by law, regulation or administrative action in Member States concerning the provision of audiovisual media services ${ }^{7}$ (Directive 2010/13/EU). This directive regulates issues such as: audiovisual media service (linear and non-linear), audiovisual commercial communication, TV advertising and teleshopping, sponsorship and product placement. In addition, the Directive also sets rules to protect minors from the risks associated with traditional television broadcasting and on-demand audiovisual services.

According to Art. 1(1)(j) of the Directive 'surreptitious audiovisual commercial communication' means the representation in words or pictures of goods, services, the name, the trade mark or the activities of a producer of goods or a provider of services in programmes when such representation is intended by the media service provider to serve as advertising and might mislead the public as to its nature. Such representation shall, in particular, be considered as intentional if it is done in return for payment or for similar consideration. 'Sponsorship' means any contribution made by public or private undertakings or natural persons not engaged in providing audiovisual media services or in the production of audiovisual works, to the financing of audiovisual media services or programmes with a view to promoting their name, trademark, image, activities or products (Art. 1(1)(k)). 'Product placement' according to Art. 1(1)(m) means any form of audiovisual commercial communication consisting of the inclusion of or reference to a product, a service or the trademark thereof so that it is featured within a programme, in return for payment or for similar consideration.

The Directive 2010/13/EU establishes two prohibitions important in the context of native advertising: one regarding hidden advertising (Art. 9(1)(a)), the second on the use of subliminal techniques (Art. 9(1)(b)). Member States and the Commission shall encourage media service providers to develop codes of conduct regarding inappropriate audiovisual commercial communications, accompanying or included in children's programmes, of foods and beverages containing nutrients and substances with a nutritional or physiological effect, in particular those such as fat, trans-fatty acids, salt/sodium and sugars or excessive intakes of which in the overall diet are not recommended (Art. 9). 
This Directive imposes a ban on product placement (Art. 11 (2)), providing for exceptions where such action is permitted (Art. 11(3) and (4)).

In light of the above mentioned regulations of EU directives, which Member States should transfer to internal legal orders, the literature emphasizes the role of proper marking of all forms of native advertising (Żebrowska, Ciechanek, 2016). However, in light of the assumptions of this form of advertising, which is to be an integral part of the media content, in practice its creators will be tempted to circumvent the requirement of unambiguous indication that the materials presented are of advertising character.

In online advertising, the previously described technique called sly product placement is increasingly being used. In order to stimulate the demand for the product, well-known people (celebrities) from the world of fashion or sport in social media "gently but insidiously" promote the product. For example, they upload their photos onto Facebook on which there are also logos of brands or characteristic shapes that allow the user to recognize the producer/company. Therefore, the question arises, whether in the context of these techniques of influencing the recipient, such behaviour should be considered legally permissible.

In the first place, it should be noted that the definition of audiovisual media services only covers such a television broadcast or an audiovisual on-demand service, which are massmedia services, i.e. they are intended to be received by a significant part of the general public and could have a clear impact on it. Its scope should, however, be limited to services within the meaning of the TFEU, and thus cover all types of economic activities. Therefore, the regulation should not be subject to essentially non-commercial activities that do not compete with television broadcasting; such as private websites and services consisting of delivering or distributing audiovisual content created by private users for sharing or exchange within interest groups (Matlak, 2010: 149). It should also be pointed out that the definition of audiovisual media services should include mass media for the provision of information, entertainment and education to the general public. However, it should not refer to any form of private correspondence, such as e-mails sent to a limited number of recipients. The definition of an audiovisual media service also should not include services whose main purpose is not to provide broadcasts, where the transmission of audiovisual content is not the main objective, but rather a minor part of the service. For example, websites that contain only ancillary audiovisual elements, such as animated graphic elements, short advertising spots or information related to a product or service that is not an audiovisual service (Matlak, 2010: 150).

According to Art. 1(1)(d) of the Directive 2010/13/EU, a "'media service provider' means the natural or legal person who has editorial responsibility for the choice of the audiovisual content of the audiovisual media service and determines the manner in which it is organised". The broadcaster, according to the directive, is the entity providing television broadcasts to recipients. When determining the entity to which obligations regarding the content of the audiovisual content is provided, the focus is on the actual control over the selection of such materials and the way they are compiled. It seems that 


\section{LEXONOMICA \\ A. Nowak-Gruca: Selected Legal Problems of Online Advertising}

the regulations of the Directive for the case of sly product placement will only be applicable by analogy.

In this context, it is difficult to recognize that the EU directives provided in this section sufficiently determine the boundaries of online advertising. However, doubts arise whether all forms of human activity, especially on the Internet, should be regulated by law.

As far as audiovisual media services are concerned, product placement should be clearly marked. Thus, the question arises whether the same rules should apply to the Internet and social media? The answer to this question will certainly be debated by EU legislators for the foreseeable future.

For the demarcation of legal boundaries of online advertising, the recipient is not to be forgotten. Since the entry into force of the Directive 2005/29/EC, the CJEU has recognized the necessity of examining its impact on a hypothetical average consumer who is sufficiently well-informed, attentive and careful enough, taking into account social, cultural and linguistic factors (Tischner, 2006: 238). Nevertheless, when determining the consumer's pattern, one should also take into account the type of transaction, the public, specific predispositions and characteristics of consumers to whom the offer is addressed. At the same time, it should be pointed out that EU actions should aim at educating the consumer so that he/she is able to adapt to the dynamics of the internal market.

Finally, it is worth paying attention to the problem of distinguishing advertising from information. Literature assumes that the information message can be considered as an advertisement only if, in addition to providing information, its main purpose is to encourage the purchase of goods (Grzybczyk, Jagielska, 2012: 63). Thus, when assessing whether the message is of advertising or only informational character, the advantage of the informative or incentive layer should be taken into account, taking into account the language, form and medium of the statement. In the context of native advertising this approach does not seem to be sufficient, which is why, on the basis of the considerations discussed above, the need to clearly mark this form of advertising as the basic condition of its legality should be emphasized again.

\section{Conclusion}

After analyzing the problems of advertising on the Internet, it is not difficult to notice that online advertising is fundamentally different from traditional advertising. The Internet creates a specific form of communication that can be placed somewhere between mass communication and individual communication. The Internet is also an extremely attractive advertising medium, because it has specific marketing features that are unavailable in the case of other media, such as the press, radio, television, etc. In EU law, we might find many advertising restrictions on specific products or services. However, there are no regulations that would apply to online advertising in a comprehensive manner. Product restrictions are aimed at eliminating the advertising of products or 
services that are harmful to health and violate generally accepted ethical standards. Alcohol, tobacco and prescription drugs are generally excluded from advertising, while the advertising of paramedicaments requires certain, explicit information to be shown to the consumer to use them properly. These restrictions are fully applicable to online advertising.

The issue of Internet advertising is complicated because its recipient has practically no chance to avoid the advertised content, which significantly differentiates the recipient of e-advertising from the recipient of the advertisement via other electronic media, who independently decides whether he/she wants to „receive” the advertisement. The recipient of online advertising is also not often aware of the legal rules in force in the field of advertising. Online advertising tries to keep the recipient's attention for as long as possible, and it has much larger capabilities in this area than other form of advertising. In this context, the most invasive the forms of advertising which have been indicated above should be considered as violating the rules of fair competitions.

Against the background of the analyses presented above, it might also be concluded that the limit of integrity of online advertising is determined by its designation, which unambiguously indicates the nature of the content presented. Depending on the material in which it appears, these may be the terms such as: "advertising", "promotion", "sponsored", "partner content developed in cooperation with the brand", etc. Any forms of advertising hiding, in the context of the previously presented provisions, it must be considered inadmissible. Often, this will be in contradiction with the interests of online advertising creators, because the results of consumer behaviour research indicate that in fact the excess of information traditional forms of advertising do not fulfill their role. It turned out that if the advertisement (e.g. product placement) is obvious and ostentatious, then the product promoted in this way in the eyes of recipients becomes less attractive. People do not like to be manipulated and this is reflected in the results of the psychological researches. However, when a product is not shown in an intrusive way, for example it appears in the background, it turns out to be more attractive to the recipients. In everyday life people are forced to make many decisions under uncertain conditions, without having enough information to analyze all available data. The cognitive errors associated with it can be a strong temptation for marketing and advertising specialists in order to use them to influence decisions we make outside of our consciousness. Therefore, it seems that the problem of misleading or concealed advertising will require rethinking in the near future, in particular in the context of its impact on the hypothetical average consumer, who may not be so well informed, attentive enough and cautious, as is apparent from the model adopted in the EU. Therefore, when determining the pattern of the consumer - recipient of advertising messages - one should take into account not only the type of transaction, the public, consumer characteristics, but above all the ability to make free and error-free choices in the context of advertising techniques used to influence shopping decisions. In this context it is difficult to recognize that the EU directives provided in this article sufficiently determine the boundaries of online advertising. Doubts arise whether all forms of human activity, especially on the Internet, should be regulated 


\section{LEXONOMICA \\ A. Nowak-Gruca: Selected Legal Problems of Online Advertising}

by law. The answer to this question will certainly belong to the EU legislators for some time.

Online advertising is a relatively young and very dynamically growing field and because of its rapid growth, the law must catch up and decide what is and is not morally right, as legal problems have arisen as marketers have become more devious in their marketing to get their message across to the public. There is no overall regulation in EU law regarding online advertising. Thus, the general rules governing issues related to advertising should be applied accordingly for advertising on the Internet, taking into account the specificity of this form of advertising. The phenomenon of the Internet and the rapid and hard to predict development of online marketing make it impossible to address all legal issues in one article.

\section{Notes}

${ }^{1}$ See https://sharethrough.com/nativeadvertising/ (access: 28. 4. 2018).

${ }^{2}$ There are examples of Robert Lewandowski's photographs on the Internet that show certain products or brands, see e.g. S. Morgan, LEW BEAUTY Robert Lewandowski shows he's head and shoulders ... the sly product placement, The Sun,

https://www.thesun.co.uk/sport/football/2656046/robert-lewandowski-shows -hes-head-andshoulders-above-the-rest-with-sly-product-placement / (access: 28. 1. 2018).

${ }^{3}$ OJ L 376, 27. 12. 2006, p. 21-27.

${ }^{4}$ See joined cases C-34/95, C-35/95 and C-36/95, Konsument ombudsmannen (KO) v De Agostini (Svenska) Förlag AB and TV-Shop i Sverige AB, ECLI:EU:C:1997:344.

${ }^{5}$ OJ L 149, 11. 6. 2005, p. 22-39. See Art. 6 of that directive.

6 See case C-611/14, Criminal proceedings against Canal Digital Danmark A/S, ECLI:EU:C:2016:800.

${ }^{7}$ OJ L 95, 15. 4. 2010, p. 1-24.

\section{References}

Barta, J., Markiewicz R. (1998) Internet a prawo (Cracow: Universitas).

Bartosz, W., Wojdynski, B. W., Evans, N. J. (2015) Going Native: Effects of Disclosure Position and Language on the Recognition and Evaluation of Online Native Advertising, Journal of Advertising, pp. 45(2), 157-168, DOI: 10.1080/00913367.2015.1115380.

Brehm, J. W. (2009) A theory of psychological reactance, in: Organization change: a comprehensive reader, Burke, W. W., Lake, D., Paine, J. W. (eds.) (San Francisco: J-B Warren Bennis Series).

Chan Yun, Y. (2009) Effects beyond click-through: Incidental exposure to web advertising, Journal of Marketing Communications, 15(4), pp. 227-246.

Grzybczyk, K. (2008) Prawo reklamy (Warszava: Wolters Kluwer Polska).

Grzybczyk, K., Jagielska, M. (2012) Obowiązek informacyjny wobec konsumenta a reklama, in: Reklama. Aspekty prawne, Namysłowska, M. (ed.) (Warszawa: Wolters Kluwer).

Edelman, B., Ostrovsky, M., Schwarz, M. (2007) Internet Advertising and the Generalized SecondPrice Auction: Selling Billions of Dollars Worth of Keywords, American Economic Review, 97(1), pp: 242-259. DOI: 10.1257/aer.97.1.242. 
Lee, N., Broderick, A. J., Chamberlain, L. (2007) What is 'neuromarketing'? A discussion and agenda for future research, International Journal of Psychophysiology, 63(2), pp. 199-204, https://doi.org/10.1016/j.ijpsycho.2006.03.007.

Makowiec, A. (2014) Prawne aspekty reklamy w sieci - zagadnienia wybrane, Kultura, Media, Teologia, 18, pp. 9-28.

Manic, M. (2015) The Rise of native advertising, Bulletin of the Transilvania University of Braşov Series V: Economic Sciences, 8(57) No. 1, pp. 53-58.

Matlak, A. (2010) Dyrektywa o audiowizualnych usługach medialnych, Zeszty Naukowe Uniwersytetu Jagielońskiego. Prace z Prawa Wlasności Intelektualnej, No 2, pp. 127-147.

Tischner, A. (2006) Model przeciętnego konsumenta w prawie europejskim, Kwartalnik Prawa Prywatnego, 1, pp. 232-233.

Tutaj, K., Reijmersdal, E. (2012) Effects of online advertising format and persuasion knowledge on audience reactions, Journal of Marketing Communications, 18(1), pp. 5-18.

Żebrowska, B., Ciechanek, Ł, (2016) Przewodnik po reklamie natywnej. Definicje, formy, kanały dystrybucji, zasady transparentności, prognozy, iab•polska, https://www.iab.org.pl/wpcontent/uploads/2016/12/Przewodnik-po-reklamie-natywnej.pdf, access 16.1.2018. 